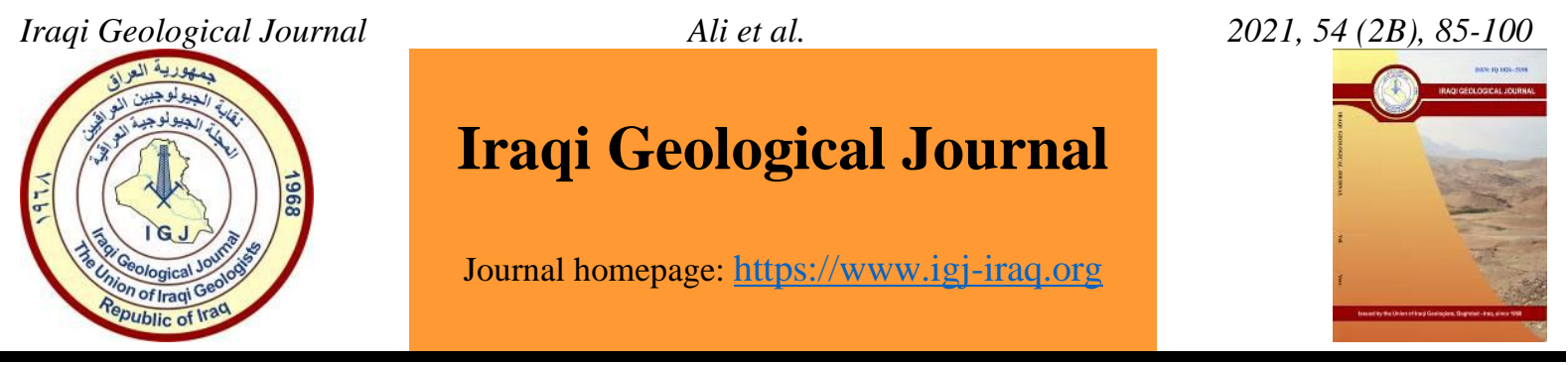

\title{
Water Phase Inclination Theory for Hydraulic Conductivity Determination of Vadose Zones in Shallow Water Table Systems
}

\author{
Arkan Radi Ali ${ }^{1}$, Dhiaa Neama Jabbar ${ }^{1}$, Kareem Fhadil Abood ${ }^{1}$ and Najah M. L. Al Maimuri ${ }^{1, *}$ \\ ${ }^{1}$ Technical Institute of Babylon, AL-Furat AL-Awsat Technical University (ATU), Iraq \\ * Correspondence: najahml@yahoo.com
}

Received: 1 January 2021; Accepted: 25 May 2021; Published: 31 August 2021

\begin{abstract}
Water Phase Inclination is an innovative theory for hydraulic conductivity and determination of vadose zone overlying shallow water table systems. It was originated and analytically derived from Darcy's Law and based on some physio-mechanical properties of soil. Al-Musayab area of $176 \mathrm{Km}^{2}$ at Mesopotamian region, mid-Iraq was undertaken as a case study. It consists of unconsolidated quaternary deposits and is usually finer-grained than the underlying pebbly sandstone with Mediterranean weather. The Experimental part was divided into field tests which include double ring infiltrometer tests, water table depth measurements and sampling of 32 undisturbed soil samples of surface layers scattered over the study area Whereas lab tests include; the falling and constant head permeability, grain size distribution (sieve and hydrometer analysis), soil specific gravity, direct shear tests and the measuring of Water Phase Inclinations. Angle $\varnothing$ a glassy infiltration box is an experimental device that was manufactured to measure the Water Phase Inclination angle and aquifer simulation. It is found a generalized linear relationship between $\phi$ and the angle of internal friction which is valid for $\phi \geq 23.37$ with correlation factor $\mathrm{R}^{2}=0.99$ and both angles depend on soil texture. The $\mathrm{k}$ values estimated by WPI theory and that measured by traditional techniques offer a linear relationship with acceptable Root Mean Square Error equals $0.0642<0.1$ the max allowable limit and correlation factor $R^{2}=0.96$, pointing out to the reliability and stability of the Water Phase Inclination results.
\end{abstract}

Keywords: Hydraulic conductivity; Unsaturated zone; Double-ring infiltrometer; Water phase inclination angle; Angle of internal friction; Root mean square error

\section{Introduction}

Due to the presence of several unfavorable factors that make the measurement of the hydraulic properties of non-disturbed soils in a laboratory not so accurate due to human and devices errors and soil disturbance due to field sampling, leads to searching for a more accurate method of $\mathrm{k}$ measuring than the traditional tests such as falling and constant heads tests. The Water Phase Inclination theory was issued to originate a standard and more accurate method for measuring $\mathrm{k}$ in unsaturated soil overlying shallow aquifers, which previous studies did not directly address. In the current research, the thickness of the unsaturated zone (groundwater depth beneath the soil surface) was measured and entered as input data in the WPI model for $\mathrm{k}$ estimate. Historically, a number of researchers have accomplished serious work in this field such as Donhal et al. (2010) who explored a semi-empirical

DOI: $10.46717 /$ igj.54.2B.8Ms-2021-08-28 
approach for obtaining near-saturated $\mathrm{k}$ by disk infiltrometer. The analysis is based on 3D numerical modeling and compared with two other expressions. Results showed the superiority of the approach but was failed for fine-textured soils due to a capillary which is not adequately addressed by existing models. Viliam et al. (2011) used a numerical method to estimate $\mathrm{k}$ depending upon relative stone content (stoniness) and size-shape stony parts. The method depends on Darcy's experiment using 2D-Hydrus model to four soil textures. The numerical results were used to derive a relationship between $\mathrm{k}$ and stoniness with different stones' diameters. Lai et al. $(2010,2012)$ undertook the effect of inner ring infiltrometer diameter and depth by using 6 inner and 6 outer diameters sizes and 24 sets of driven depths for $\mathrm{k}$ measurements. Results reveal that inner diameter influents $\mathrm{k}$ more than outer diameter and larger inner diameter results in more accurate $\mathrm{k}$ measurements. Driven depths $5-15 \mathrm{~cm}$ were recommended to minimize soil disturbance and converging the $\mathrm{k}$ results to real values. Latorre et al. (2013) used a new method for sorptivity (S) and k estimate depending upon Haverkamp et al. (1994) equation which proven to be valid for short to medium times. A number of soil samples of 264 were tested by infiltrometer with $10 \mathrm{~cm}$ in diameter. Field measurements proved that the NSQE method offered better estimates of soil hydraulic properties. Mohammad et al. (2015) used a soil electrical conductivity and resistivity as a measure to k. Electrical resistivity tomography (ERT) and EM38 used to develop multiple datasets to define spatiotemporal water content $(\mathrm{W})$ variation and $\mathrm{k}$ estimation under site conditions in Lisbon, Prtogal. Experiments proved that the soils are approximately homogenous and semi-pervious with spatiotemporal $\mathrm{W}>10 \%$ and $3<\mathrm{k}<9 \mathrm{~cm} /$ day. Latorre et al., (2015) estimated $\mathrm{S}$ and $\mathrm{k}$ from full time infiltration cumulative curve. The method is called the Numerical Solution of Haverkamp equation (NSH) which satisfied for 12 synthetic soil simulated with HYDRUS-3D. The work indicates that NSH is an important technique for estimating transient hydraulic properties. Salima et al. (2016) proved the adjustment for the retention curve $\theta(\mathrm{h})$ is insufficient for describing the hydraulic conductivity curve $\mathrm{K}$ $(\theta)$ and spatiotemporal variation of soil $\theta(\mathrm{z})$ moisture. Adornis and Isaiah (2016) investigated the effects of soil texture on crust formation and steady state infiltration rate (SSIR). It was concluded when crust formation was decreased, SSIR increased with increase in aggregate size. If a contaminant increases in clay, it is resulting in a decrease in primary mineral and Kaolinite existence. Sung (2016) examined the interactions effects between water flow and air in unsaturated soils under heavy rainfall. Air-water and 2-phase flow analysis were carried out to exploring pore-air pressure effect on rainfall infiltration. Results revealed that an increase in air-pore pressure during infiltration resulting in flow delay was induced. Such water-air interaction is significantly affected the slope stability behavior. Kargas et al. (2017) used a mini disc infiltrometer to measure loam and silty clay soils to obtain hydrodynamic properties; water retention $\theta(\mathrm{h})$ and $\mathrm{k}$. The water retention results were compared with mini disc infiltrometer (MDI) user manual of Decagon Devices (2007), whereas the k results were compared with Dohnal et al. (2010) equation. Their method offered similar results of $\theta(\mathrm{h})$ and k. Amir et al. (2018) presented an inverse study for estimating $\mathrm{k}$ and solute transport in subsurface drainage system in Iran. The sensitivity analysis of SWAP model was used for simulating the output results by using $\mathrm{n}$ shape parameter, lateral $\mathrm{k}$, impermeable layer depth (W) and a shape parameter. It was found the NashSutcliffe Efficiency (NSE) values were 0.63 and 0.79 for drainage discharge and salinity respectively in Amirkabir area whereas (NSE) values for Shoaybiyeh area were 0.83, 0.95 and 0.89 for drainage discharge, groundwater depth, sanitary respectively. Latorre et al (2018) estimated $\mathrm{k}$ and $\mathrm{S}$ from the transient cumulative infiltration curve by using different values of $\beta$ parameter to assessing its effect in $1 \mathrm{D}$ and $3 \mathrm{D}$ infiltration curve for loamy sand, silty and loam soils. It was indicated that $\mathrm{k}$ and $\mathrm{S}$ can be precisely obtained by using a constant $\beta$. Rahmati et al (2019a) used an alternate function to quasi-exact implicit (QEI) formulation of Harverkamp' Equation to estimate $\mathrm{k}$ and $\mathrm{S}$ by using cumulative infiltration for longer times. The 3-term approximation expansion, QEI formulation, good fittings, measured accumulative infiltration curve and accuracy of $\mathrm{S}, \mathrm{k}$ and $\beta$ parameters were compared. It was found that 
3-term has larger validity time interval than 1\&2-term approximate expansion resulting in accurate estimate of k. Aparimita et al. (2019) used four soil types, namely; sand, sandy loam, silt and loam to evaluate infiltration characteristics. The Van Genuchten's model was used for verifications. It was evident for sandy loam, Hydrus offered appreciable results whereas for sandy and loam soil were underestimated and for silt was overestimated. Biplab and Sreeja (2019) studied the variation between double ring (DRI), mini-disc (MDI) and tension disc (TI) infiltrometers at two infiltration field conditions within two seasons in north India. It was found that initial infiltration rate $\mathrm{F}_{\mathrm{O}}$ was highest and lowest final $\mathrm{F}_{\mathrm{C}}$ for DRI in most cases. It was also concluded a particle size fraction has insignificant correlation with $\mathrm{k}$. The $\mathrm{k}$ values by MDI and TI were approximately $2 / 3$ of DRI. Fernández-Gálvezab et al. (2019) presented a cost-effecive Beerkan Estimation of Soil Transfer parameters (BEST) by using a ring infiltrometer for deriving $\mathrm{k}$ and water retention functions. The best methods were tested for several synthetic soils and the results indicates that these methods offer consistent hydraulic functions. Rahmati et al (2019b) investigated the relationship between $\mathrm{k}$ and the permeability in air $\mathrm{K}_{\mathrm{w}}$ of soil at a specified $\mathrm{W}$ by using 27 soil samples, since $\mathrm{k}$ test by air is more rapid and nondestructive. They used multilinear regression to develop pedo-transfer function which showed more acceptability and accuracy. Moreternándeza et al. (2019) carried out two phases to estimating $\mathrm{k}$ and $\mathrm{S}$; the first was a double-slope infiltration which based on short-medium time transient infiltration curve (Tr)and short-medium transient and steady-state infiltration step (Mx) for 20 soils site under different water repellency degrees. It was concluded that $\mathrm{k}$ and $\mathrm{S}$ estimated with $\mathrm{Mx}$ were $26 \%$ more than the estimated with Tr. Al-Dabbas et al. (2020) used a modeling approach to manage the shallow water table system overlying Bai Hassan formation by using a measured transmissivity of 40 wells in Kurdistan-Iraq. Lie et al (2020) used a new method to estimate Kostiakov-Lewis model parameters; $\mathrm{k}$, a and $\mathrm{F}_{\mathrm{O}}$ by using 240 samples in Shanxi province, China. It was concluded that support vector machine (SVM) and Physical soil properties (PSS) are strong tool in estimating Kostiakov-Lewis infiltration parameters. Al-beyati et al. (2021) used a porosity image analysis to originate 3D model for $\mathrm{k}$ determination by taking 72 cores of soil samples from Balad, mid-Iraq. The $\mathrm{k}$ values were ranged between 1.51-8.97 $\mathrm{m} / \mathrm{d}$.

In this paper, the WPI theory was adopted that aims to measure $\mathrm{k}$ of unsaturated soils overlying shallow groundwater regimes relying on $\theta$ and $\theta$ ' to avoid the usual errors originating during soil testing and sampling disturbance. To solidifying this theory, a lab model which was manufactured of class to establish a $\theta^{\prime}$ relationship through simulating a laboratorial shallow aquifer. It is large enough to be filled with soils brought from different field sites to representing the saturated and unsaturated soil horizons to observing carefully the natural deep percolation phenomena in shallow groundwater regime. The obtained inclination angle $\theta$ ' was enabled to derive a mathematical model based on Darcy's Law which was used to estimate $\mathrm{k}$ correspondingly and the aquifer boundary conditions. The estimated $\mathrm{k}$ values obtained by WPI model were compared to a corresponding traditional $\mathrm{k}$ results which were estimated by constant and falling head permeameters. The correlation factor between the measured $\mathrm{k}$ with the traditional methods and by that obtained by WPI model is 0.957 with RMSE equals 0.0642 < 0.1 which is reliable in engineering practices.

\section{Materials and Methods}

\subsection{Physics of Vadose Zone Saturation}

The saturation process produced by the double ring infiltrometer starts with a point water source under the base of infiltrometer within a surface soil layer. Then it is enlarged to a spherical water plume in earlier stages of testing with time proceeding as illustrated in Fig. 1a. Since groundwater is shallow therefore becomes possible for the spherical plume of the infiltrated water finally contacts the groundwater surface to producing an inclined water phase with WPI angle $\theta$ '. The outer water phase 
boundary of the water plume will continue expanding in 3D until it stabilizes with an inclination surface depending on the soil texture after it has been in full contact with groundwater as in Fig.1. After contacting and as time proceeding, a steady state and Darcy's Law conditions for water flow through soil pores has been dominated.

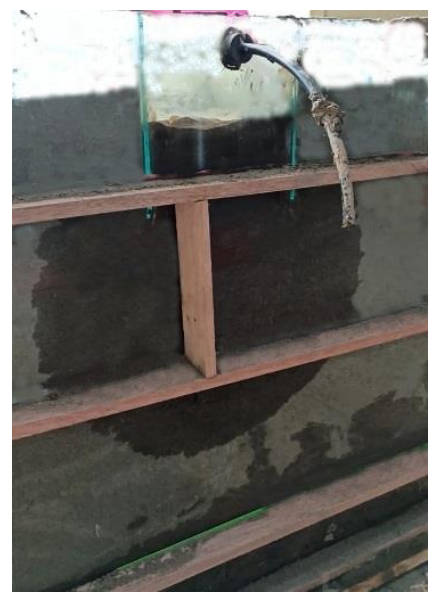

(a) Lab model

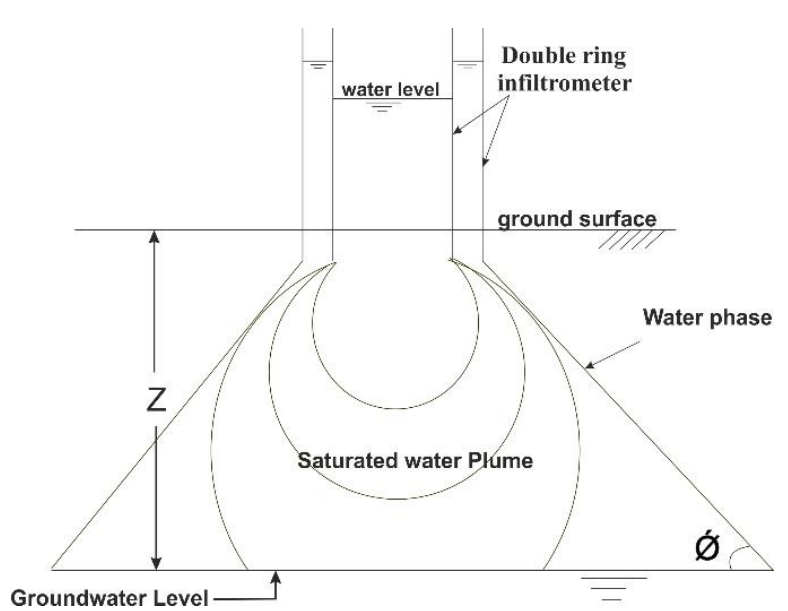

(b) schematic model

Fig.1. Infiltration phenomenon in the different stages of water phase advance

It is worth to mention that why the outer water phase boundary may take many probable inclinations? This is depending upon soil texture of the considered zone. This concept may theoretically demonstrate by Fig. 2 which shows three probable soil types. If it is supposed the whole soil zone texture is gravelly soil, correspondingly the water move speedily and vertically downward with an inclination angle may close to $90^{\circ}$. When the soil texture gets finer, one expects the angle accordingly converges to smaller values as a result of soil resistivity to water flow. In general, the angles of inclinations of water phase $\theta$ 'may be:

$$
\theta_{\text {gravel }}^{\prime}>\theta^{\prime}{ }_{\text {Sand }}>\theta^{\prime} \text { Clay loam }
$$

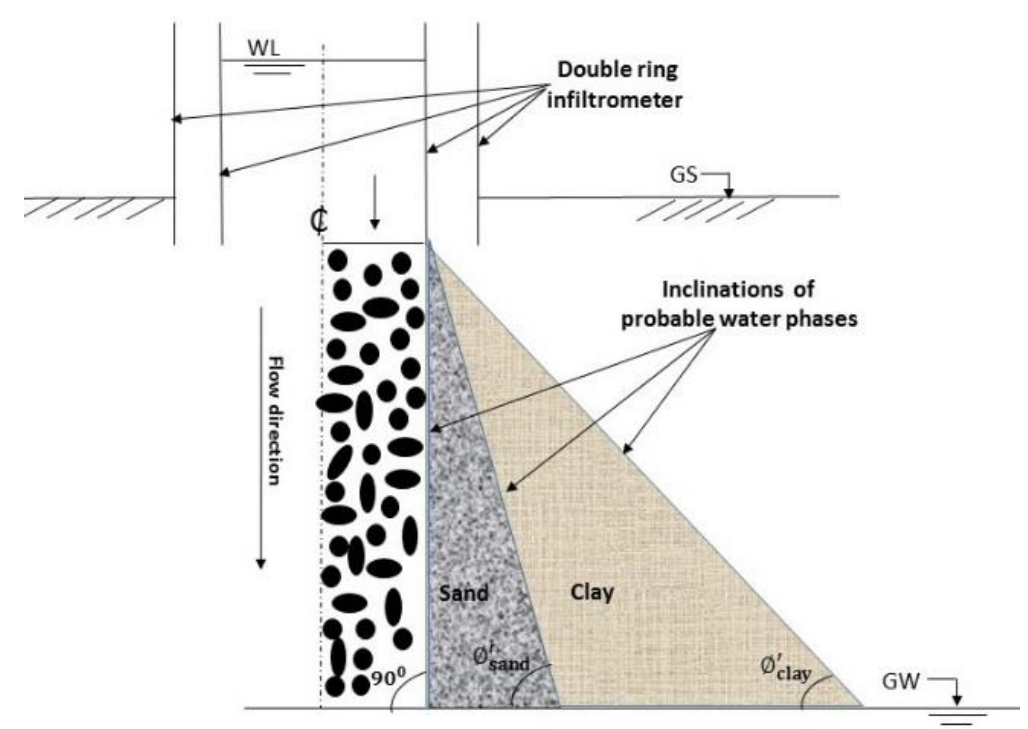

Fig.2. Probable water phases inclinations for different soil textures 
In engineering practice, the angle $\theta^{\prime}$ is difficult to measure in clayey soils because due to the activity of capillary phenomena and its resistivity to water flow. Fortunately, the angle of internal friction $\left(\theta^{\prime}\right)$ is also depend upon soil texture, therefore become clear both $\theta$ and $\theta^{\prime}$ depend on soil texture. Accordingly, it is expected there is a direct relationship between the two angles as:

$\theta=\mathrm{CF}(\theta)$ or $\theta^{\prime}=\mathrm{C}_{1} \mathrm{~F}(\theta)$

Where $\mathrm{C}=1 / \mathrm{C}_{1}$ is some coefficient

\subsection{Mathematical Background of WPI Theory in Vadose Zone}

The subsurface hydrodynamic saturated system of Fig. 3 is governed by Darcy's Law if the boundary conditions are defined and justified as a water flow in full saturation. To simplifying a mathematical derivation of the current theory, two assumptions are undertaken under steady state condition:

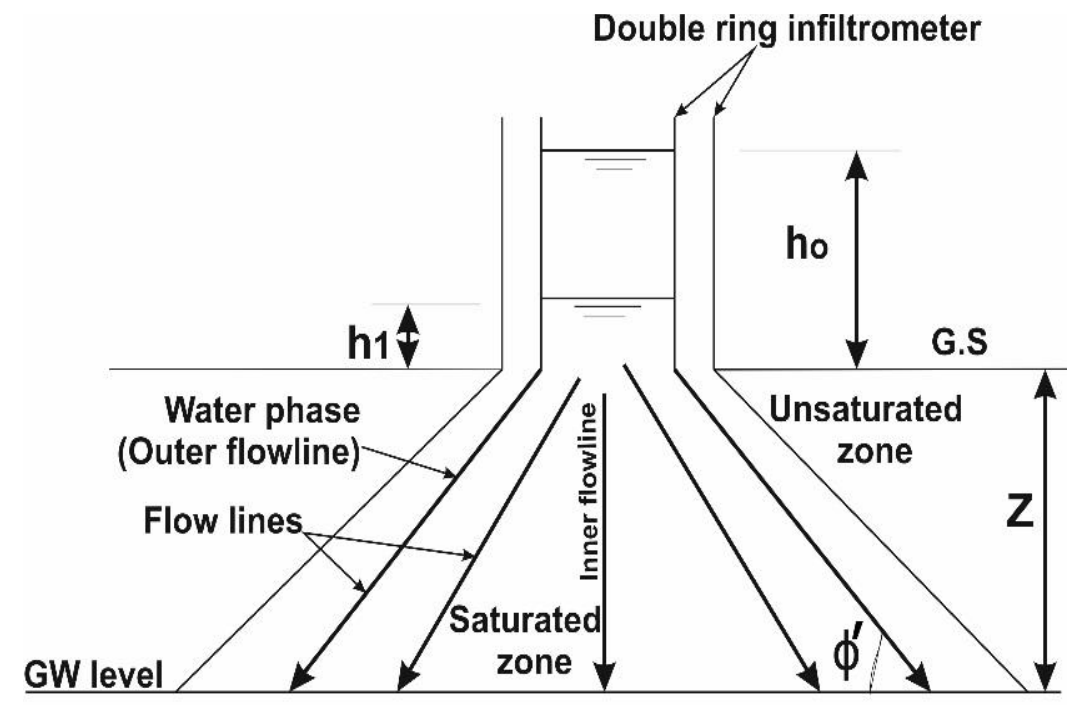

Fig.3. Double ring infiltrometer setup and WPI model

a) The cross-sectional area of the zone of saturation (A) perpendicular to downward flowlines is taken as the mean area of the inner infiltrometer ring cross sectional area and the area of contact between the zone of saturation and the groundwater. This mathematically is expressed as:

$$
A=\frac{\pi}{4}\left(D_{i}^{2}+2 z D_{i} \cot \emptyset^{\prime}+2 z^{2} \cot ^{2} \emptyset^{\prime}\right)
$$

b) the average length of the flow lines within the zone of saturation is taken as the mean of the inner flowlines under the centerline of the infiltrometer and the outer flowlines lengths which is geometrically estimated as

$$
L=\frac{z}{2}\left(\csc \emptyset^{\prime}+1\right)
$$

Where:

$D_{i}$ : Inner diameter of double ring infiltrometer, $h_{o}$ : Initial infiltrometer water head at steady infiltration capacity (after the saturated plume adhering groundwater and at zero time), $h_{1}$ : water head after time t, $z$ : depth of groundwater beneath soil surface.

On the basis of the infiltrometer geometry of Fig. 3 and Darcy' Law conditions (1856): 


$$
a d h=-k \frac{h}{L} A d t
$$

Where, $\mathrm{a}$ is an infiltrometer inner cross-sectional area, $\mathrm{h}$ is the applied water head, $\mathrm{A}$ is the average cross-sectional area of a saturated zone and $\mathrm{z}$ is the groundwater depth and assumed equal to L, Chow (1964). By separation of variables of both sides of Eq.3 and making the necessary integrals to a specified limit of $\int_{h_{0}+z}^{h_{1}+z}$, one may obtain the form of falling head permeameter as;

$$
k=\frac{a L}{A t} \ln \frac{h_{0}+z}{h_{1}+z}
$$

A substitution of Equations ( 1 \& 2) in Eq.(4) leads to

$$
k_{\mathrm{WPI}}=\frac{z\left(\csc \emptyset^{\prime}+1\right) D_{i}^{2}}{2 t\left(D_{i}^{2}+4 z D_{i} \cot \emptyset^{\prime}+4 z^{2} \cot ^{2} \emptyset^{\prime}\right)} \ln \frac{h_{0}+z}{h_{1}+z}
$$

$K_{W P I}$ is the saturated hydraulic conductivity of vadous zone.

\subsection{Validation of WPI Model}

The current form of Eq. (5) can only be applied in a saturated media and this can be fulfilled when the infiltration rate becomes in steady state condition. The full explanation demonstrated in Fig. 4, the exponential function of the infiltration rates versus time may consist of two parts:

i) Transient infiltration through an unsaturated soil is usually encountered (reach a), Latorre et al. (2018).

ii) Steady saturated water infiltration is governed by Darcy's law and shown in (reach b). At which the infiltrated flow lines become in contact with upper face of groundwater Fig.1b, therefore Eq.5 can be applied.

Obviously if a rainstorm of long duration occurred and/or the downward infiltration under double ring infiltrometer test obeys Darcy's law, Eq. (5) can be applied because water flow in such circumstances is under saturation condition.

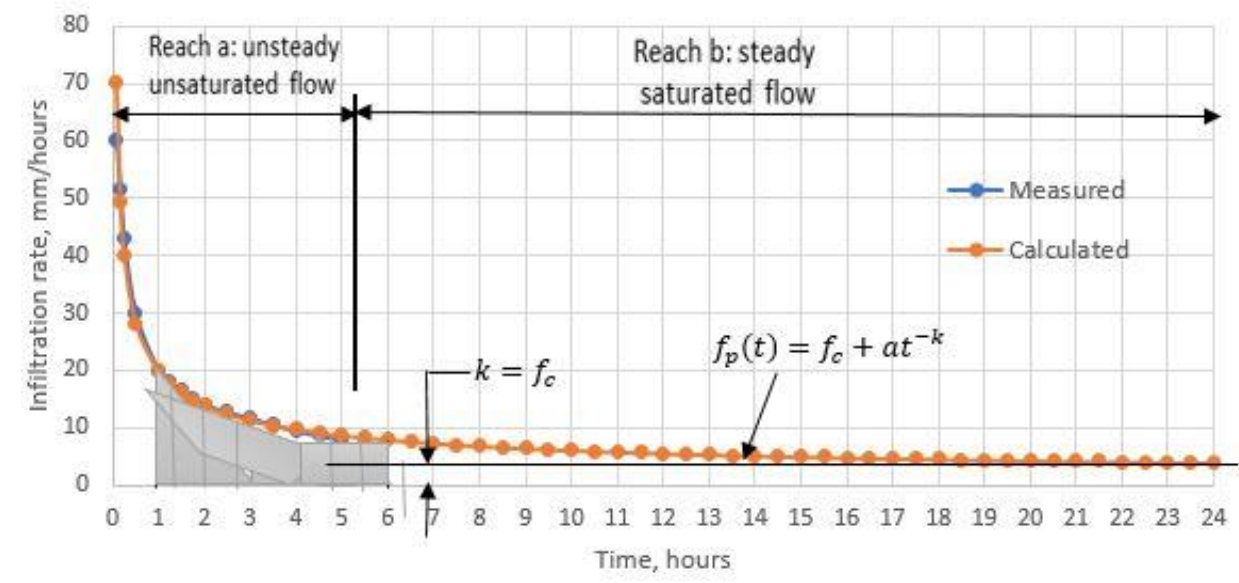

Fig.4. Transient water infiltration in unsaturated zone over shallow groundwater aquifers 
Horton and similar mathematical models explain the physical behavior of infiltration phenomena in unsaturated zone, Latorre et al. (2015 \& 2018). This is explained in Fig. 4. As observed the infiltration rate curve never be in steady state $\left(F_{c}=\right.$ Constant $)$, if the water table is deep, but it will be constant $\left(F_{c}=\right.$ Constant $)$ if the water table is shallow.

\subsection{Physical Properties of Vadous Zone}

The current analysis requires many laboratorial and field tests. Some of them have been carried out on undisturbed soil samples brought from the site i.e.

\subsubsection{Lab tests}

1- Falling head test of undisturbed soil samples according to BS 1377-5:1990 and ASTM D2435 - 04 standard test for 1D consolidation properties of soils.

2- Direct shear test of soil according to ASTM standard D-3080 on soils under consolidated drained conditions.

3- Specific gravity $\left(\mathrm{G}_{\mathrm{s}}\right)$ test of soil according to ASTM D891 - 18 .

4- Dry density $\left(Y_{d}\right)$ test of soil according to ASTM D7263 - 09(2018) e2.

5- Grain size distribution test of soil samples according to ASTM D7928 - 17.

6- Water phase inclination angle test.

\subsubsection{Field tests}

Other tests were carried out at the field i.e.

1. Groundwater depth test according to ASTM D6000 / D6000M - 15e1.

2. Double ring infiltrometer test according to ASTM D3385 - 18.

\subsubsection{Porosity estimate ( $n)$}

The porosity of the vadous zone was estimated by the form, Al Maimuri (2018 \& 2020):

$n=1-\frac{y d}{G_{s} Y_{w}}$

Where $\left(\mathrm{Y}_{6}\right)$ is the unit weight of water at $(25 \mathrm{C})$

\subsubsection{Measurement methodology}

The current determination procedure of $\mathrm{k}$ encountered a set of difficulties, including the costs of sampling, landowner approval and the time factor. Briefly, thirty-two locations were selected for testing and sampling spread over the considered region. In each site three undisturbed soil samples were taken in order to get the average value of three tests. Also, the infiltration test was repeated three times to obtain the average infiltration rate curve.

In general, the whole work consists of two steps:

1- Field work which requires to carry out the sequential following steps:

a- Achieving double ring infiltrometer test.

b- Measuring the groundwater depth below ground surface.

c- Sampling undisturbed soil sample.

2- Carrying out the tests

\subsection{Experimental Determination of $\theta$,}

In order to measure the angle of inclination of the water phase, a lab model was manufactured to simulate a shallow water table system which may be called a Glass Infiltration Box (GIB), Fig.5. 


\subsubsection{GIB constituents and aquifer simulation}

The whole structure of the box is made of glass. The soil sample is placed inside the GIB which consists of two parts:

1- The lower part: It is the part in which the soil is placed so that it is partially submerged with water to a depth of $60 \mathrm{~cm}$ below soil surface level. This water represents groundwater level in nature.

2- The upper part: represents the part that is filled with water to a $15 \mathrm{~cm}$ water head meanwhile it is installed with $15 \mathrm{~cm}$ below soil surface.

The water head should be applied for a time period enough to penetrate the full depth of the unsaturated horizon and touch the groundwater and continues to flow steadily. The angle of inclination $\left(\theta^{\prime}\right)$ of the water phase is then measured.

3- A sample of soil then is taken to estimate the angle of internal friction by direct shear test.

4- Establishing a mathematical relationship between both set of angles $\theta$ and $\theta$ ' the measured values for all field specimens. A selected stages of water phase advance are graphically shown in the laboratorial GIB of Fig. 6.

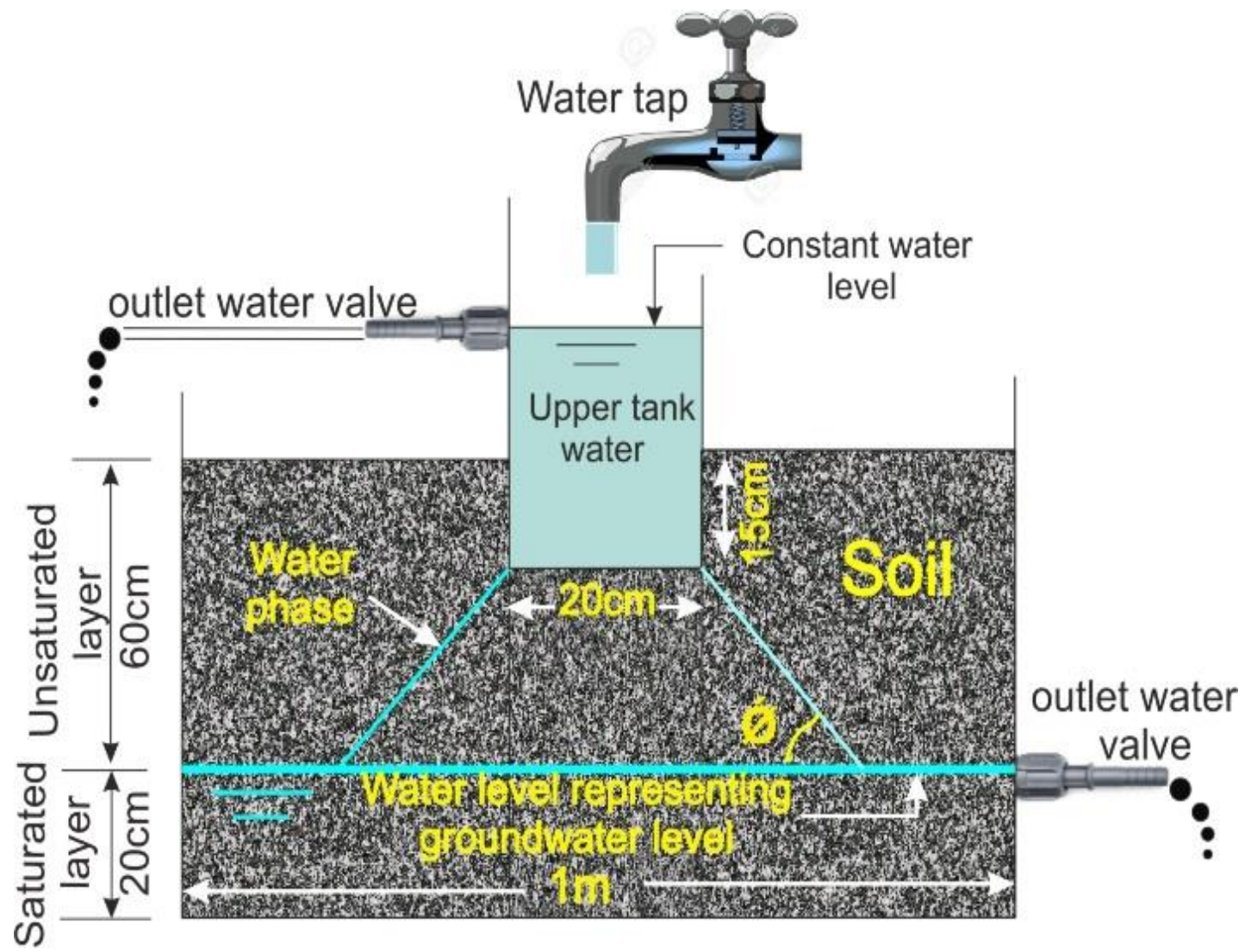

Fig.5. Graphical sketch for the GIB

The water plume starts to expand radially under the water source as shown in Fig. 6a and continues progression downward until becomes in contact with water table as in Fig 6.. After a period of time which depending on soil texture above the water table, the infiltration water flows steadily and the water phase slope instantaneously becomes constant with a constant angle of inclination $\theta$ ' as in Fig. 6. 


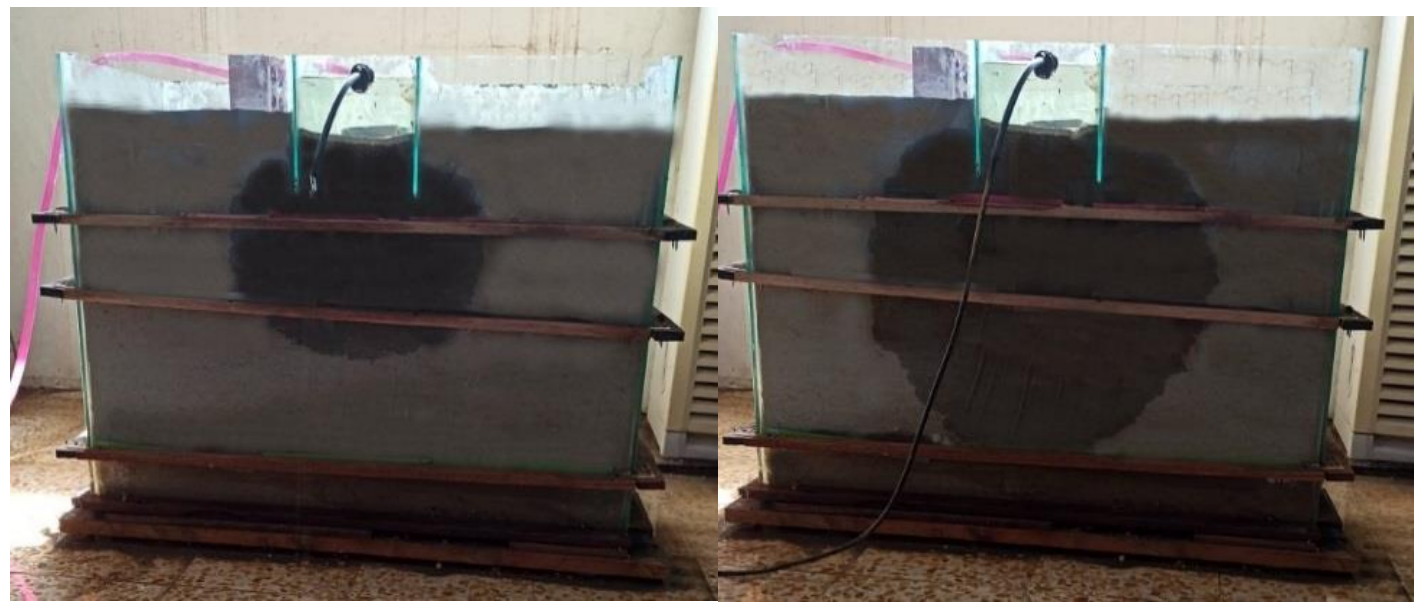

(a) Stage 1

(b) Stage 2

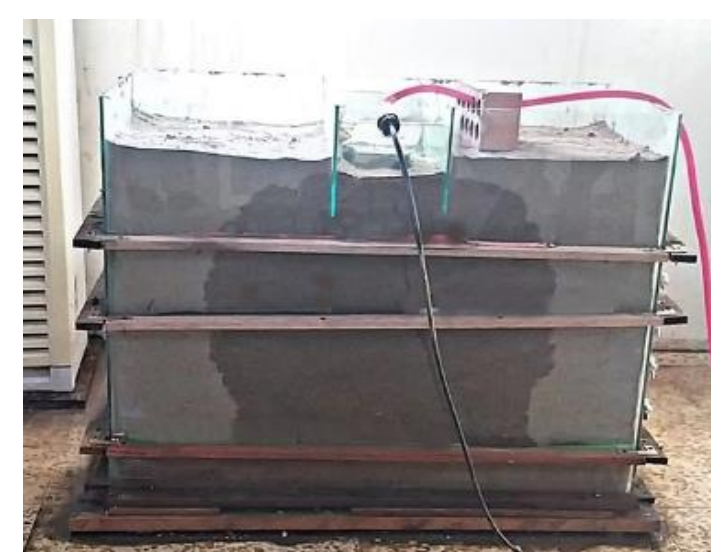

(c) Stage 3

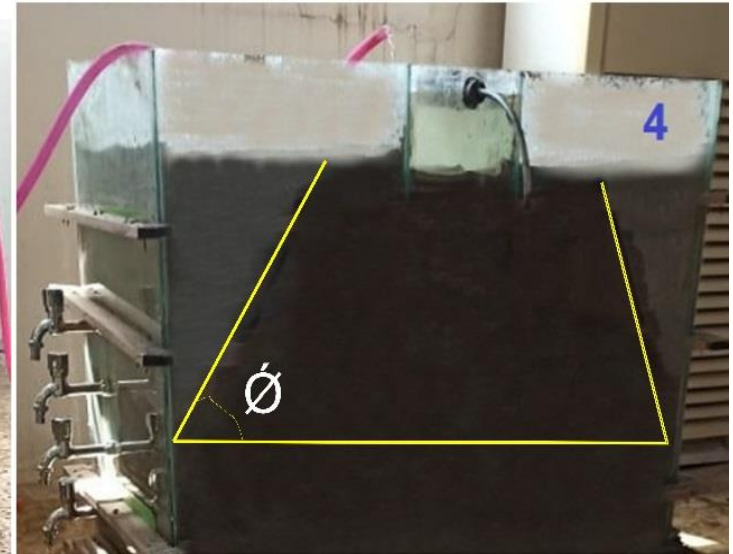

(d) Stage 4

Fig.6. Stages of water phase boundaries advance to reach a state of stability

\subsection{Analytical Methodologies of $k$ Determination}

In this section the WPI technology has been issued to estimation of $\mathrm{k}$ for the vadose zone in shallow groundwater regimes depending on the WPI angle measurements by using the GIB and Eq.5. The determination of $\mathrm{k}$ starts with the angle of internal friction and WPI angle measurements and then a mathematical relationship between them should be originated.

\subsection{Root Mean Square Error (RMSE) of KWIP}

Statistically, the RMSE is preferred to be used for finding the mass error between two sets of data as indicated by Chai and Drexler (2014) of the form:

$$
\begin{aligned}
& R M S E=\sqrt{\frac{1}{N}} \sum_{I}^{N}=1\left(e_{i}\right) 2 \\
& e_{i}=x_{i}-y_{i}
\end{aligned}
$$

Where $\mathrm{n}$ is a number of observations and $e_{i}$ is the error. 


\subsection{Infiltration Model}

In this analysis, the measured infiltration rates were represented graphically by the Power Infiltration Model adopted by Al Maimuri (2018) of the form:

$$
\begin{aligned}
& f_{p}(t)=f_{c}+a t^{-k} \\
& A F_{P}(t)=f_{c} t+\frac{a t^{1-k}}{1-k}
\end{aligned}
$$

Where $F_{p}(t)$ is a water infiltration rate at time $(\mathrm{t}),\left(\mathrm{F}_{\mathrm{c}}\right)$ is a final infiltration rate occurred in the end of a rainstorm or at the end of double ring infiltrometer test, a and $\mathrm{k}$ are some constants depend on the infiltration data series and $A F_{P}(t)$ is the accumulated infiltration depth after time (t).

\subsection{Case Study}

An arbitrary area of $176 \mathrm{~km}^{2}$ at Al-Musayab within the Mesopotamian region, mid-Iraq was selected as a case study since shallow groundwater was encountered as shown in Fig. 7. Generally, the features of soils are fine texture (Buringh, 1960). It is covered with different types of quaternary deposits which are unconsolidated and usually finer-grained than the underlying pebbly sandstone of Dibdibba and Injana formations (late Miocene-Pliocene). Sediments of the Holocene age cover the surface. They encompass fluvial and lacustrine deposits. The natural processes forming geological settings have been changed by human activities for several thousand years and recently many artificial irrigation canals have been constructed (Jassim and Goff, 2006).

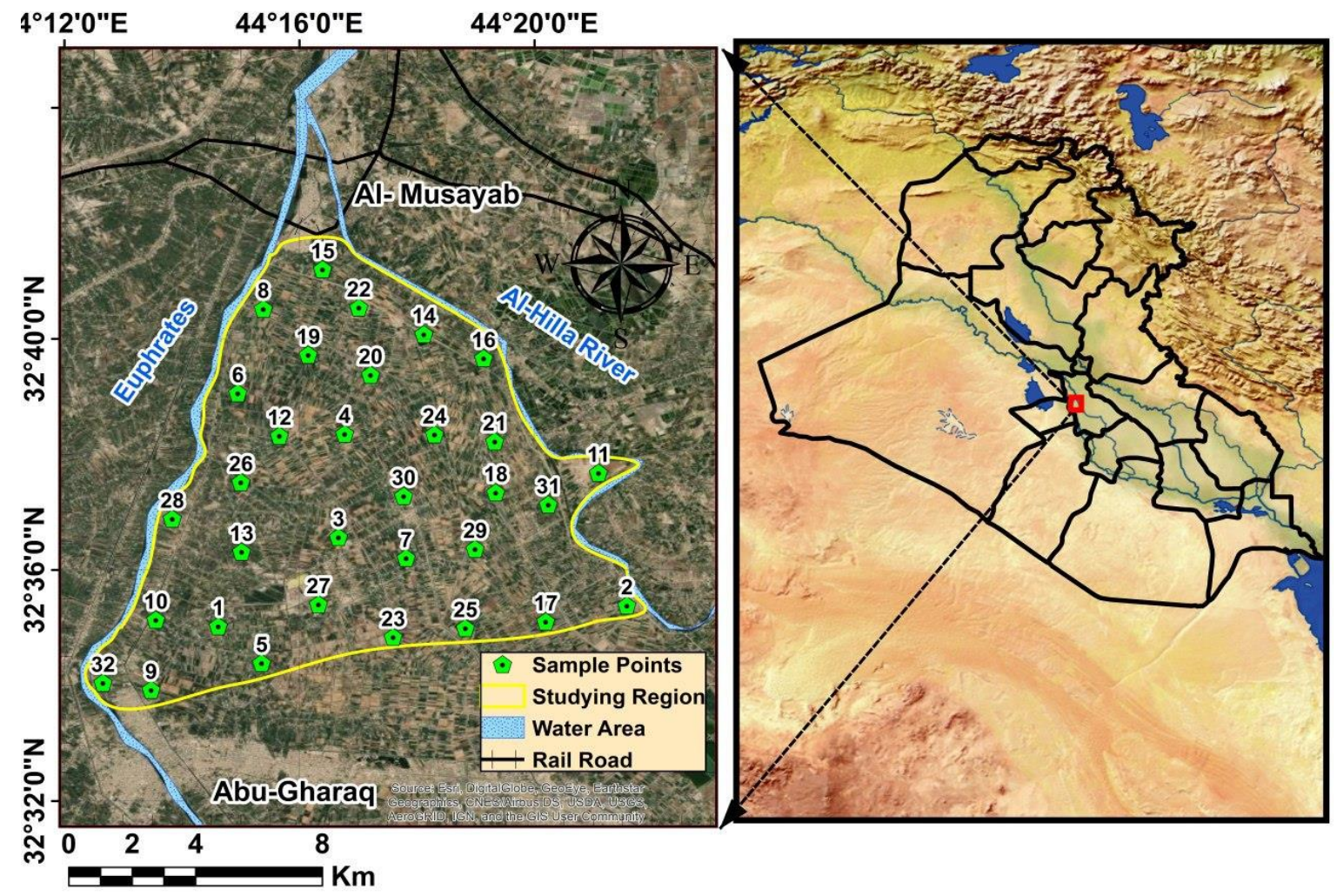

Fig.7. Location map of Al-Musayab area and sampling sites coordinates 


\section{Results and Discussion}

\subsection{Measured and Estimated Data}

Global coordinate of 32 sites within the case study area shown in Fig.7 were fixed in Table.1 by using Global Positioning System (GPS) for field tests including; double ring infiltrometer test and groundwater depth in addition to sampling disturbed and undisturbed soil samples. The disturbed soil samples were chosen with adequate quantities to measure the $\theta$ and $\theta^{\prime}$ by using the direct shear and GIB respectively. The undisturbed soil samples were used to measure the hydraulic conductivity ( $\mathrm{k}_{\text {lab }}$ ) by using the falling and constant head tests, hydraulic conductivity ( $\mathrm{k}_{\mathrm{WPI}}$ ) by utilizing WPI theory, dry density, specific gravity and porosity. All these properties of soil samples were included in Table 1 and Table 2. Whereas soil grains size distribution and infiltration rate were represented graphically in Fig. 8 and Fig.9 respectively due to a huge amount of data.

Table1. Average values of laboratorial tests, field measurements and estimated data

\begin{tabular}{|c|c|c|c|c|c|c|c|c|c|}
\hline \multirow{2}{*}{$\begin{array}{l}\text { Site } \\
\text { No. }\end{array}$} & Latt, (N) & Long, (E) & \multirow{2}{*}{$\begin{array}{c}K_{l a b} \\
(\mathbf{c m} / \mathbf{d a y})\end{array}$} & \multirow{2}{*}{$\begin{array}{c}Y_{d} \\
(\mathrm{KN} / \mathrm{m})^{3}\end{array}$} & \multirow[t]{2}{*}{$G_{S}$} & \multirow[t]{2}{*}{$\mathbf{n}$} & \multirow{2}{*}{$\begin{array}{c}\theta \\
\left({ }^{o}\right)\end{array}$} & \multirow{2}{*}{$\begin{array}{c}\theta^{\prime} \\
\left({ }^{\circ}\right)\end{array}$} & \multirow{2}{*}{$\begin{array}{c}\mathbf{Z} \\
(\mathbf{c m})\end{array}$} \\
\hline & $"$ & o & & & & & & & \\
\hline 1 & $32^{\circ} 35^{\prime} 1.624^{\prime \prime} \mathrm{N}$ & $44^{\circ} 14^{\prime} 37.219^{\prime \prime} \mathrm{E}$ & 1.4362 & 1.636 & 2.69 & 0.392 & 29.72 & 27 & 128 \\
\hline 2 & $32^{\circ} 35^{\prime} 23.175^{\prime \prime} \mathrm{N}$ & $44^{\circ} 21^{\prime} 34.465^{\prime \prime} \mathrm{E}$ & 2.8815 & 1.52 & 2.7 & 0.437 & 30.66 & 31 & 110 \\
\hline 3 & $32^{\circ} 36^{\prime} 34.099^{\prime \prime} \mathrm{N}$ & $44^{\circ} 16^{\prime} 39.974^{\prime \prime} \mathrm{E}$ & 2.2776 & 1.755 & 2.67 & 0.342 & 31.13 & 33 & 125 \\
\hline 4 & $32^{\circ} 38^{\prime} 21.362^{\prime \prime} \mathrm{N}$ & $44^{\circ} 16^{\prime} 46.268^{\prime \prime} \mathrm{E}$ & 2.015 & 1.600 & 2.67 & 0.400 & 31.02 & 32.5 & 126 \\
\hline 5 & $32^{\circ} 34^{\prime} 23.450^{\prime \prime} \mathrm{N}$ & $44^{\circ} 15^{\prime} 21.409^{\prime \prime} \mathrm{E}$ & 2.8081 & 1.764 & 2.66 & 0.336 & 30.90 & 32 & 110 \\
\hline 6 & $32^{\circ} 39^{\prime} 3.720^{\prime \prime} \mathrm{N}$ & $44^{\circ} 14^{\prime} 57.056^{\prime \prime} \mathrm{E}$ & 1.2936 & 1.557 & 2.69 & 0.421 & 28.54 & 22 & 111 \\
\hline 7 & $32^{\circ} 36^{\prime} 12.425^{\prime \prime} \mathrm{N}$ & $44^{\circ} 17^{\prime} 49.001^{\prime \prime} \mathrm{E}$ & 1.7125 & 1.616 & 2.67 & 0.394 & 30.78 & 31.5 & 126 \\
\hline 8 & $32^{\circ} 40^{\prime} 31.213^{\prime \prime} \mathrm{N}$ & $44^{\circ} 15^{\prime} 23.154^{\prime \prime} \mathrm{E}$ & 1.4461 & 1.605 & 2.68 & 0.401 & 28.78 & 23 & 112 \\
\hline 9 & $32^{\circ} 33^{\prime} 55.636^{\prime \prime} \mathrm{N}$ & $44^{\circ} 13^{\prime} 28.565^{\prime \prime} \mathrm{E}$ & 0.8414 & 1.500 & 2.7 & 0.444 & 26.98 & 15.4 & 115 \\
\hline 10 & $32^{\circ} 35^{\prime} 8.307^{\prime \prime} \mathrm{N}$ & $44^{\circ} 13^{\prime} 33.409^{\prime \prime} \mathrm{E}$ & 0.6311 & 1.566 & 2.72 & 0.424 & 26.56 & 13.6 & 110 \\
\hline 11 & $32^{\circ} 37^{\prime} 40.958^{\prime \prime} \mathrm{N}$ & $44^{\circ} 21^{\prime} 5.528^{\prime \prime} \mathrm{E}$ & 1.121 & 1.540 & 2.66 & 0.421 & 17.50 & -24.87 & 111 \\
\hline 12 & $32^{\circ} 38^{\prime} 19.458^{\prime \prime} \mathrm{N}$ & $44^{\circ} 15^{\prime} 39.616^{\prime \prime} \mathrm{E}$ & 1.6742 & 1.522 & 2.69 & 0.434 & 30.07 & 28.5 & 111 \\
\hline 13 & $32^{\circ} 36^{\prime} 18.960^{\prime \prime} \mathrm{N}$ & $44^{\circ} 15^{\prime} 0.998^{\prime \prime} \mathrm{E}$ & 1.1232 & 1.568 & 2.67 & 0.412 & 28.73 & 22.8 & 120 \\
\hline 14 & $32^{\circ} 40^{\prime} 4.899^{\prime \prime} \mathrm{N}$ & $44^{\circ} 18^{\prime} 7.085^{\prime \prime} \mathrm{E}$ & 2.0599 & 1.563 & 2.68 & 0.417 & 31.16 & 33.1 & 120 \\
\hline 15 & $32^{\circ} 41^{\prime} 12.254^{\prime \prime} \mathrm{N}$ & $44^{\circ} 16^{\prime} 23.700^{\prime \prime} \mathrm{E}$ & 1.205 & 1.614 & 2.65 & 0.391 & 29.29 & 25.2 & 125 \\
\hline 16 & $32^{\circ} 39^{\prime} 39.966^{\prime \prime} \mathrm{N}$ & $44^{\circ} 19^{\prime} 8.138^{\prime \prime} \mathrm{E}$ & 1.6399 & 1.805 & 2.67 & 0.324 & 20.00 & -14.26 & 112 \\
\hline 17 & $32^{\circ} 35^{\prime} 6.573^{\prime \prime} \mathrm{N}$ & $44^{\circ} 20^{\prime} 11.554^{\prime \prime} \mathrm{E}$ & 2.787 & 1.635 & 2.67 & 0.388 & 31.16 & 33.12 & 102 \\
\hline 18 & $32^{\circ} 37^{\prime} 20.541^{\prime \prime} \mathrm{N}$ & $44^{\circ} 19^{\prime} 20.529^{\prime \prime} \mathrm{E}$ & 1.3897 & 1.665 & 2.67 & 0.376 & 28.99 & 23.9 & 114 \\
\hline 19 & $32^{\circ} 39^{\prime} 43.547^{\prime \prime} \mathrm{N}$ & $44^{\circ} 16^{\prime} 9.000^{\prime \prime} \mathrm{E}$ & 2.3139 & 1.746 & 2.67 & 0.346 & 31.14 & 33.02 & 112 \\
\hline 20 & $32^{\circ} 39^{\prime} 22.812^{\prime \prime} \mathrm{N}$ & $44^{\circ} 17^{\prime} 12.699^{\prime \prime} \mathrm{E}$ & 1.6668 & 1.834 & 2.67 & 0.313 & 29.95 & 28 & 113 \\
\hline 21 & $32^{\circ} 38^{\prime} 13.562^{\prime \prime} \mathrm{N}$ & $44^{\circ} 19^{\prime} 19.519^{\prime \prime} \mathrm{E}$ & 1.57221 & 1.756 & 2.67 & 0.342 & 29.62 & 26.6 & 115 \\
\hline 22 & $32^{\circ} 40^{\prime} 32.575^{\prime \prime} \mathrm{N}$ & $44^{\circ} 17^{\prime} 0.717^{\prime \prime} \mathrm{E}$ & 1.2374 & 1.841 & 2.66 & 0.308 & 29.39 & 25.6 & 128 \\
\hline 23 & $32^{\circ} 34^{\prime} 50.397^{\prime \prime} \mathrm{N}$ & $44^{\circ} 17^{\prime} 35.762^{\prime \prime} \mathrm{E}$ & 2.2868 & 1.691 & 2.67 & 0.367 & 31.13 & 33 & 112 \\
\hline 24 & $32^{\circ} 38^{\prime} 20.885^{\prime \prime} \mathrm{N}$ & $44^{\circ} 18^{\prime} 18.013^{\prime \prime} \mathrm{E}$ & 1.4791 & 1.763 & 2.67 & 0.340 & 29.25 & 25 & 116 \\
\hline 25 & $32^{\circ} 34^{\prime} 59.742^{\prime \prime} \mathrm{N}$ & $44^{\circ} 18^{\prime} 49.537^{\prime \prime} \mathrm{E}$ & 1.6742 & 1.782 & 2.68 & 0.335 & 30.19 & 29 & 114 \\
\hline 26 & $32^{\circ} 37^{\prime} 31.244^{\prime \prime} \mathrm{N}$ & $44^{\circ} 15^{\prime} 0.285^{\prime \prime} \mathrm{E}$ & 1.803 & 1.780 & 2.68 & 0.336 & 30.43 & 30 & 112 \\
\hline 27 & $32^{\circ} 35^{\prime} 24.472^{\prime \prime} \mathrm{N}$ & $44^{\circ} 16^{\prime} 19.469^{\prime \prime} \mathrm{E}$ & 0.404 & 1.712 & 2.69 & 0.363 & 26.81 & 14.66 & 120 \\
\hline 28 & $32^{\circ} 36^{\prime} 53.287^{\prime \prime} \mathrm{N}$ & $44^{\circ} 13^{\prime} 50.097^{\prime \prime} \mathrm{E}$ & 2.485 & 1.815 & 2.81 & 0.354 & 32.78 & 40 & 110 \\
\hline 29 & $32^{\circ} 36^{\prime} 21.948^{\prime \prime} \mathrm{N}$ & $44^{\circ} 18^{\prime} 59.454^{\prime \prime} \mathrm{E}$ & 2.564 & 1.821 & 2.79 & 0.347 & 33.96 & 45 & 128 \\
\hline 30 & $32^{\circ} 37^{\prime} 16.894^{\prime \prime} \mathrm{N}$ & $44^{\circ} 17^{\prime} 46.436^{\prime \prime} \mathrm{E}$ & 2.981 & 1.819 & 2.83 & 0.357 & 34.67 & 48 & 129 \\
\hline 31 & $32^{\circ} 37^{\prime} 8.029^{\prime \prime} \mathrm{N}$ & $44^{\circ} 20^{\prime} 14.221^{\prime \prime} \mathrm{E}$ & 2.133 & 1.870 & 2.99 & 0.374 & 31.98 & 36.6 & 113 \\
\hline 32 & $32^{\circ} 34^{\prime} 2.917^{\prime \prime} \mathrm{N}$ & $44^{\circ} 12^{\prime} 39.483^{\prime \prime} \mathrm{E}$ & 2.715 & 1.831 & 2.88 & 0.364 & 34.5 & 47.27 & 110 \\
\hline
\end{tabular}

\subsection{Grain Size Distribution}

A good understanding of water infiltration phenomena in the vadose zone overlaying the shallow water table regimes requires an accurate identification of the grains size distribution of the soil texture. The grains size distribution of soil samples versus 32 sites were tested, analyzed and represented graphically in Fig. 8. 
Table 2. Hydraulic conductivity by falling and constant head permeameter, and WPI theory

\begin{tabular}{|c|c|c|c|}
\hline Field No. & $\theta$ & KWPI, $\left(\mathrm{cm} \mathrm{day}^{-1}\right)$ & $K_{L A B},\left(\mathrm{~cm} \mathrm{day}^{-1}\right)$ \\
\hline 1 & 27 & 1.352087 & 1.4362 \\
\hline 2 & 31 & 2.292353 & 2.8815 \\
\hline 3 & 33 & 2.027515 & 2.2776 \\
\hline 4 & 32.5 & 1.939701 & 2.015 \\
\hline 5 & 32 & 2.431455 & 2.8081 \\
\hline 6 & 22 & 1.277816 & 1.2936 \\
\hline 7 & 31.5 & 1.828893 & 1.7125 \\
\hline 8 & 23 & 1.344542 & 1.4461 \\
\hline 9 & 15.4 & 0.723362 & 0.8414 \\
\hline 10 & 13.6 & 0.669318 & 0.6311 \\
\hline 11 & 22.65 & NIL & 1.121 \\
\hline 12 & 28.5 & 1.748804 & 1.6742 \\
\hline 13 & 22.8 & 1.050499 & 1.1232 \\
\hline 14 & 33.1 & 1.986488 & 2.0599 \\
\hline 15 & 25.2 & 1.138793 & 1.205 \\
\hline 16 & 28.1 & NILE & 1.6399 \\
\hline 17 & 33.12 & 2.692028 & 2.787 \\
\hline 18 & 23.9 & 1.244675 & 1.3897 \\
\hline 19 & 33.02 & 2.249426 & 2.3139 \\
\hline 20 & 28 & 1.640495 & 1.6668 \\
\hline 21 & 26.6 & 1.455661 & 1.57221 \\
\hline 22 & 25.6 & 1.117159 & 1.2374 \\
\hline 23 & 33 & 2.246808 & 2.2868 \\
\hline 24 & 25 & 1.294 & 1.4791 \\
\hline 25 & 29 & 1.714952 & 1.6742 \\
\hline 26 & 30 & 1.882551 & 1.803 \\
\hline 27 & 14.66 & 0.415127 & 0.404 \\
\hline 28 & 40 & 2.550685 & 2.485 \\
\hline 29 & 45 & 2.574628 & 2.564 \\
\hline 30 & 48 & 3.029833 & 2.981 \\
\hline 31 & 36.6 & 1.999096 & 2.133 \\
\hline 32 & 47.27655 & 2.700604 & 2.715 \\
\hline
\end{tabular}

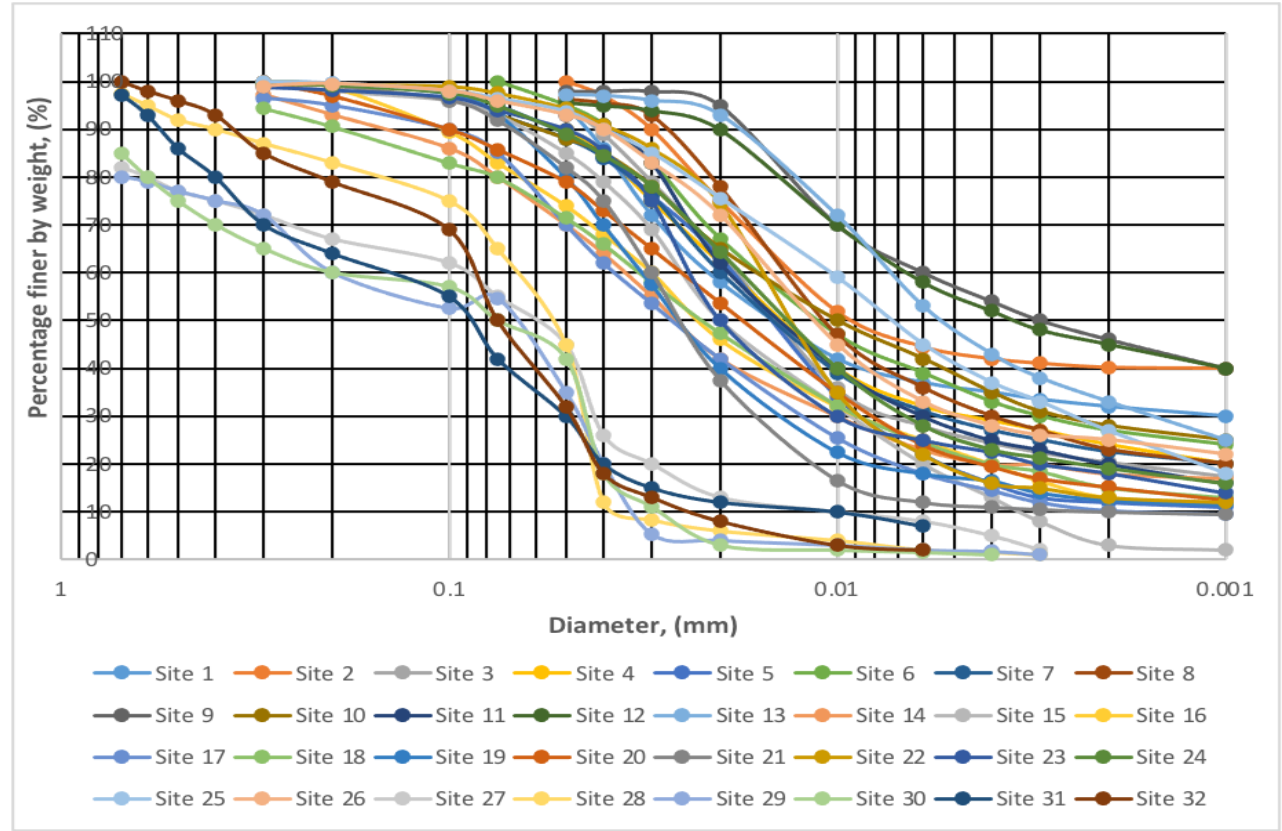

Fig.8. Grain size distribution of the field samples selected from the sites No. 1-32

\subsection{Infiltration Rate Results}

The infiltration rate of the measured data was fitted by the power model of Al Maimuri (2018) Eq. (9), then the measured data for five hours were extended to 24 hours to justifying the value of $f_{c}$ since 
before 24 hours, constant $f_{c}$ cannot be obtained. The resulting infiltration rate curves of the 32 sites were represented graphically in Fig. 9.

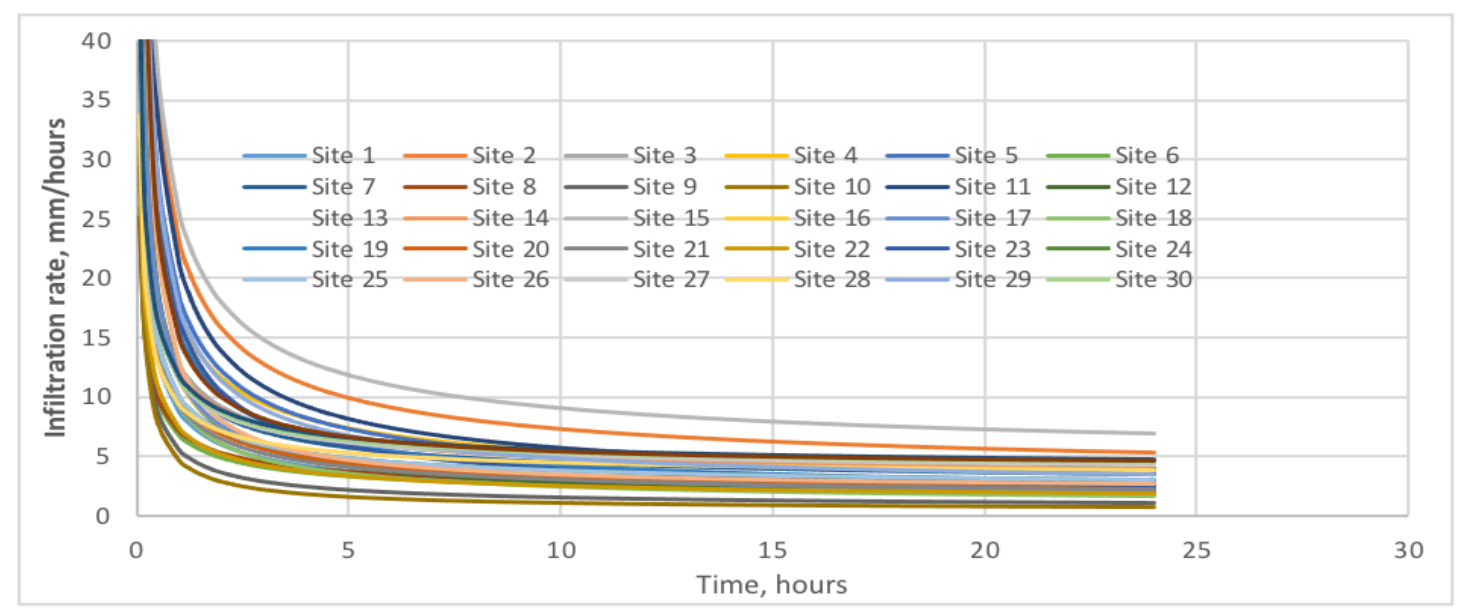

Fig.9. Infiltration rate of the field samples selected from the sites No. 1-32

\subsection{General $\theta$ '- $\theta$ Relationship Originating}

The measured angles values $\theta$ and $\theta$ ' of 32 sites which listed in Table 1 were correlated by a linear function and presented in Fig.10.

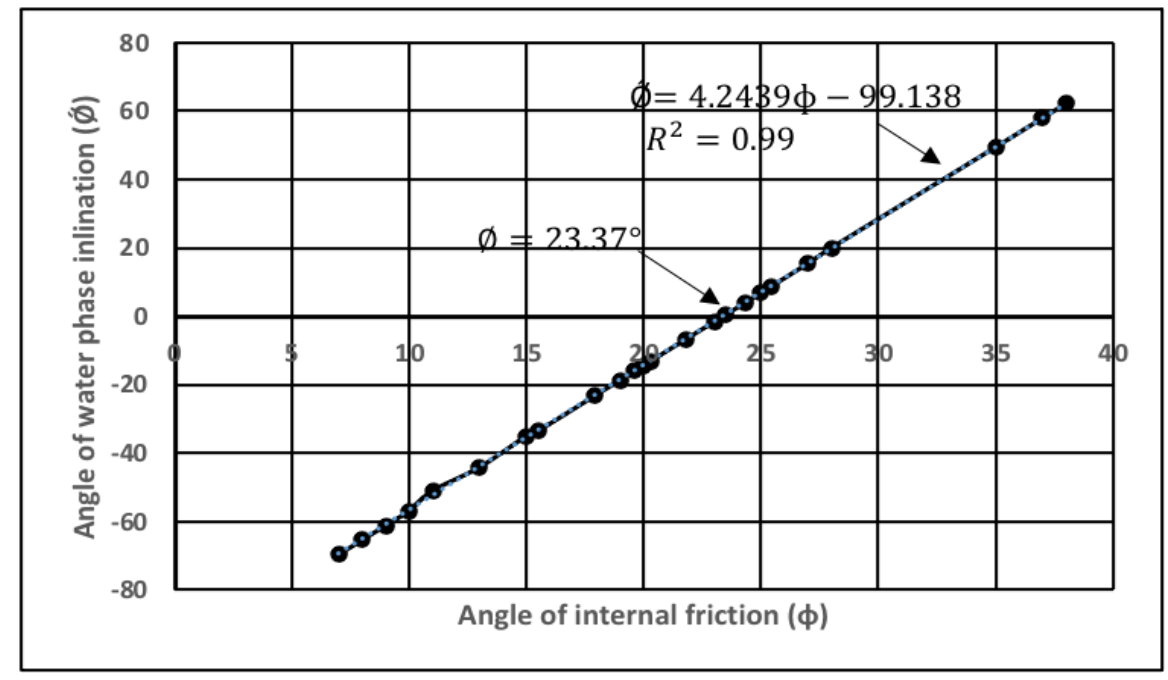

Fig.10. Linear relationship between $\theta$ and $\theta^{\prime}$

According to the results, a linear relationship was found between $\theta$ and $\theta^{\prime}$ as shown in Fig.10. The linear function of Eq.11 informs that for $\theta \leq 23.37^{\circ}$ (the point of intersection with X-axis) the angle of inclination will be negative as indicated in Fig. 10. The domain $0 \leq \theta<23.37^{\circ}$ will offer negative range of $\theta^{\prime}<\theta$. The negative values of WPI angle are trivial and insignificant which reveals that WPI angle can't be obtained. Correspondingly, becomes impossible to determining the value of $\mathrm{k}_{\mathrm{WPI}}$ for soils with angles of internal friction $\theta \leq 23.37^{\circ}$. In other word, this theory is invalid for clayey soils because the outer blurring contours of the water phase boundary. This is supported by laboratory experiments using GIB, as it was found that clayey soils do not show clear features of the water phase that can be measured.

$$
\theta^{\prime}=4.2439 \theta-99.138
$$


It is worth to mention that for $\theta<23.37^{\circ}$, the soil gets to be clayey loam which practically offers an indistinct infiltration process because of clay resistance to water motion, the activation of capillary action and water dispersion in an anisotropic media. Correspondingly, it is practically difficult to measure the WPI angle Ǿ. Briefly, it was practically concluded for soils with $\theta<23.37^{\circ}$, the angle of inclination it is neither measured by using GIB nor estimated by Eq. 11 .

\subsection{Hydraulic Conductivity by WPI Technique}

The results of $\mathrm{k}$ for the 32 sites of the vadous zone by using the WPI technique were estimated by the following steps:

1- Find the corresponding angle of internal friction $\theta$ for any soil of a specified site.

2- Estimating the angle of inclination $\theta$ ' of the water phase for the soil samples by Eq.11.

3- Using the formula of Eq.5 to estimate the hydraulic conductivity $K_{W P I}$ by measuring the angle of $\theta$ ' soil at any location.

The results were included in Table 2 and compared with the $\mathrm{k}$ obtained by the traditional techniques of falling and constant head permeameters according to BS 1377-5:1990 and ASTM D2435 - 04 standards. It is noted that $\mathrm{k}$ cannot be obtained for sites (11 and 16) because the negative values of the inclination angles as indicated in Table 1 . The correlation factor of $\mathrm{K}_{\mathrm{WPI}}$ versus $\mathrm{K}_{\mathrm{lab}}$ was found to be $\left(\mathrm{R}^{2}\right.$ $=0.9575)$ as indicated in Fig. 11 .

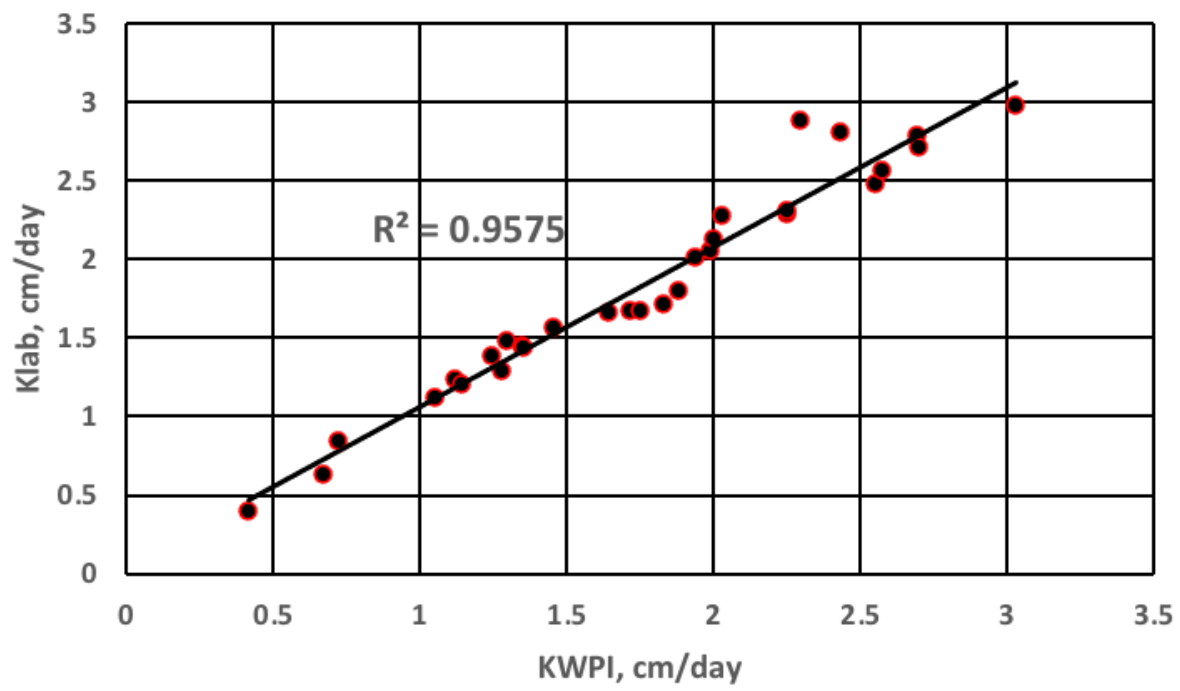

Fig.11. Correlation of $\mathrm{K}_{\mathrm{LAB}}$ versus $\mathrm{K}_{\mathrm{WPI}}$

\subsection{RMSE Analysis for $K_{W P I}$}

The RMSE as outlined by Chai and Draxler (2014) was estimated by using Eqs. (7 and 8) for the two sets of hydraulic conductivity values listed in Table 2 . It is evidently that RMSE should be $(0<$ RMSE $<1$ ) but if is $<0.1$, it is very confident as recommended by many researchers. For the current two sets of $\mathrm{k}$ listed in Table 2, it is found that the RMSE was $0.0642<0.1$.

\section{Conclusions}

It is concluded that the WPI theory which depends on field double ring infiltrometer test is more suitable and accurate for measuring the hydraulic conductivity (k) precisely than lab traditional techniques which is usually associated with many human and devices errors and soil samples disturbance. The correlation factor between the WPI hydraulic conductivity and that obtained by 
traditional lab tests is $\mathrm{R}^{2}=0.96$. The angle of internal friction $(\theta)$ and the water phase inclination angle $\theta^{\prime}$ are both depend on soil texture with a linear relationship in between them which is valid for soils with $\theta \geq 23.37^{\circ}$ and correlation factor $\mathrm{R}^{2}=0.99$.. The glass infiltration box (GIB) is proved to be suitable for simulating and testing the deep infiltration in shallow aquifers.

\section{Acknowledgements}

The authors are very grateful to the Editor in Chief Prof. Dr. Salih M. Awadh, the Secretary of Journal Mr. Samir R. Hijab. and the Technical Editors for their great efforts and valuable comments.

\section{References}

Adornis, D. N. and Isaiah, I. C. W., 2016. Physical crust formation and steady-state infiltration rate in soils dominated by primary minerals in some South African ecotopes. South African Journal of Plant and Soil, 33(1).

Albeyati, F., Abdula, R. A., and Terzi, F., 2021. Porosity and permeability measurements integration of The Upper Cretaceous in Balad Field, Central Iraq. Iraqi Geological Journal, 54, (1B).

Al Maimuri, N. M. L., 2018. Applicability of Horton model and recharge evaluation in irrigated arid Mesopotamian soils of Hashimiya, Iraq. Arabian Journal of Geoscience, 11,

Al Maimuri, N. M. L., 2020. Radon (222Rn) occurrence in quaternary deposits, annual dosage, and groundwater recirculation in Hashimiya, Iraq. Journal of Sustainable water Resource Management, 6(11).

Aparimita, P., Naik, B. G., and Sreeja, P., 2019. Estimating soil hydraulic properties using mini disk infiltrometer. ISH Journal of Hydraulic Engineering, 25,1.

ASTM D3080/D3080M-11: Standard Test Method for Direct Shear Test of Soils Under Consolidated Drained Conditions.

ASTM D3385 - 09: Standard Test Method for Infiltration Rate of Soils in Field Using Double-Ring Infiltrometer.

ASTM D5084 - 03: Standard Test Methods for Measurement of Hydraulic Conductivity of Saturated Porous Materials Using a Flexible Wall Permeameter.

Biplab, G., and Sreeja, P., 2019. A critical evaluation of measurement induced variability in infiltration characteristics for a river sub-catchment. Measurement Journal,.132, 47-59.

Buringh, P., 1960. Soils and soil conditions in Iraq, Republic of Iraq, Ministry of Agriculture, Baghdad, 323 pp.

Chai, T. and Draxler, R. R., 2014. Root mean square error (RMSE) or mean absolute error (MAE)? - Arguments against avoiding RMSE in the literature. Geoscientific model development, 7(1), 1247-1250.

Chow, V.T., 1964. Handbook of Applied Hydrology. McGraw-Hill Book Company, New York.

Darcy H., 1856. Determination of the laws of flow through sand, in Les Fontaines Publiques de la Ville de Dijon, 590-594, Victor Dalmont, Paris. (Translated and Reproduced in Physical Hydrology, edited by R. A. Freeze and W. Back, John Wiley, New York, 1983.).

Decagon Devices Inc., 2007. Mini Disc Infiltrometer, User's Manual, 5, 24.

Dohnal, M., Dusek, J., Vogel, T., 2010. Improving hydraulic conductivity estimates from mini disc infiltrometer measurements for soils with wide pore size distributions. Soil Science Society. American Journal, 74, 804811.

Fernández-Gálvezab, J., Pollaccob, J. A. P., Lassabaterec, L., Angulo-Jaramilloc, R., Carrick, S., 2019. A general beerkan estimation of soil transfer parameters method predicting hydraulic parameters of any unimodal water retention and hydraulic conductivity curves: Application to the Kosugi soil hydraulic model without using particle size distribution data. Advances in Water Resources, 129, 118-130.

Haverkamp, R., Ross, P.J., Smettem, K.R.J., Parlange, J.Y., 1994. Three-dimensional analysis of infiltration from the disc infiltrometer. Part 2. Physically based infiltration equation. Water Resources Research 30, 29312935 ,

Horton RE., 1940. An approach toward a physical interpretation of infiltration capacity. Proc Soil Science Society American, 5, 399-417.

Jassim, S. Z., and Goff, C., 2006. Geology of Iraq, Published by Dolin, Prague and Moravian Museum, Bron in the Czech Republic, 352 pp. 
Kargas G., Londra P.A., and Valiantzas J.D., 2017. Estimation of near-saturated hydraulic conductivity values using a mini disc infiltrometer. Water Utility Journal, 16, 97-104.

Lai J., Luo Y. and Ren L., 2010. Buffer index effects on hydraulic conductivity measurements using numerical simulations of double-ring infiltration. SSSAJ, 74 (5), 1526-1536.

Lai J., Luo Y. and Ren L., 2012. Numerical evaluation of depth effects of double-ring infiltrometers on soil saturated hydraulic conductivity measurements. SSSAJ, 76 (3), 867-875.

Latorre, B., Peña, C., Lassa batere, L., Angulo-Jaramillo, R., and Moret-Fernández, D., 2015. Estimate of soil hydraulic properties from disc infiltrometer three-dimensional infiltration curve. Numerical analysis and field application. Journal of Hydrology, 527, 1-12.

Latorre, B., Moret-Fernándeza, D., Lassabatereb, L., Rahmatic, M., Lópeza, M. V., Angulo-Jaramillob, R., Sorandod, R., Comínd, F., Jiméneze, J. J., 2018. Influence of the $\beta$ parameter of the Haverkamp model on the transient soil water infiltration curve. Journal of Hydrogeology, 564, 222-229.

Latorre, G. B., Moret-Fernández, D., Peña-Sancho, C., 2013. Estimate of soil hydraulic properties from disc infiltrometer threedimensional infiltration curve: theoretical analysis and field applicability. Procedia Environmental Sciences, 19, 580-589.

Lei G., Fan G., Zeng,W., 2020. Estimating parameters for the Kostiakov-Lewis infiltration model from soil physical properties. Journal Soils Sediments, 20, 166-180.

Mohammad, F., Fernando, A., Monteiro, S., and Mohamed, A. K., 2015. Application of EM38 and ERT methods in estimation of saturated hydraulic conductivity in unsaturated soil. Journal of Applied Geophysics, 112, 175-189.

Moret-ernándeza D, .Latorrea B,.Ginerb M.L Ramosa J.,.Aladosb C.L, Castellanob C.,.Lópeza M.V,.Jimenezb J.J, Pueyob Y., 2019. Estimation of the soil hydraulic properties from the transient infiltration curve measured on soils affected by water repellency. Journal of Catena, 178, 298-306.

Al-Dabbas, M., Kreamer, D., Al-Shammari, A., and Jwad, A. M., 2020. Management of Bai Hassan unconfined aquifer, Lesser Zab river basin, Kurdistan Region, Iraq using a modeling approach. Iraqi Geological Journal, 53 (2B), 1-23.

Rahmati, M., Borja Latorre, B., Lassabaterec, B., Rafael, A. J., David, M. F., 2019a. The relevance of Philip theory to Haverkamp quasi-exact implicit analytical formulation and its uses to predict soil hydraulic properties. Journal of Hydrology, 570, 816-826.

Rahmati M., Neyshaboury M.R. \& Mohammadi P., 2019b. Prediction of soil hydraulic conductivity at saturation using air permeability at any individual soil water content. Journal Civil Engineering, 23, 5226-5234.

Rahmati, M., and Neyshaboury, M. R., 2016. Soil air permeability modeling and its use for predicting unsaturated soil hydraulic conductivity. SSSAJ, 80 (6), 1507-1513.

Salima, B., Ibrahim, A. I., and Ahcéne, S., 2016. Estimation of the empirical model parameters of unsaturated soils. E3S Web Conf., Volume 9, $3^{\text {rd }}$ European Conference on Unsaturated Soils - "E-UNSAT 2016".

Sung E. C., 2016. Stability analysis of unsaturated soil slopes considering water-air flow caused by rainfall infiltration. Journal of Engineering Geology, (211) 184-197.

Viliam, N., Karol, K., and Jirka, Š., 2011. Determining the influence of stones on hydraulic conductivity of saturated soils using numerical method. Geoderma Journal, 161, (3-4), 177-181. 